\title{
Análise do Programa dos Minidistritos: novos enfoques na avaliação de políticas públicas ${ }^{1}$
}

\author{
Claudia Moreira Borges ${ }^{2}$ e Dante Pinheiro Martinelli ${ }^{3}$
}

RESUMO: O trabalho tem como objetivo a análise da política pública de incentivo à implantação de minidistritos industriais em São José do Rio Preto (SP). Para a análise dos dados, empregaram-se estatística multivariada e geoprocessamento - vistos aqui como instrumentos de avaliação quantitativa que apontam diferenças locais de desenvolvimento. Os resultados do estudo apontam diferenças econômicas e sociais, comparando regiões com e sem minidistritos. A análise do programa permitiu a construção de um modelo que une políticas e atores, com o objetivo de contribuir para o desenvolvimento econômico da região, na qual estão inseridos, no contexto de alternativas endógenas de desenvolvimento.

PALAVRAS-CHAVE: minidistritos, política pública, desenvolvimento local, avaliação, indicador.

ABSTRACT: This study aims to analyse the public policy of industrial mini-districts in Sao Jose do Rio Preto (SP). Geoprocessing and multivariate analysis were used for identify the microregional differences. The results indicate economic and social differences comparing regions with and without mini-districts. The regions with mini-districts are less developed than regions without this public policy. The analysis of the program resulted in a model that link politics and actors that contribute to economic development of the regions, in a context of endogenous alternatives to development.

KEYWORDS: mini-districts, public policy, local development, evaluation, indicator.

\section{Introdução}

A busca de novas alternativas para os modelos de desenvolvimento tem motivado o estudo de novos arranjos e projetos implantados pelos governos locais. Essas políticas vêm sendo avaliadas e debatidas, uma vez que muitas se apresentam como projetos inovadores e encorajados por meio de parcerias envolvendo diversos atores sociais (ROLNIK e NAKANO, 2001).

Ao se analisarem as experiências de políticas públicas em desenvolvimento local, tem-se, usualmente, buscado compreender o processo histórico de sua elaboração e como foram

\footnotetext{
Os autores agradecem à FAPESP pelo apoio financeiro.

Professora da Fundação Escola de Comércio Álvares Penteado. Mestre em Organizações pela Faculdade de Economia, Administração e Contabilidade de Ribeirão Preto da Universidade de São Paulo. Email: claudia.borges@fecap.br.

3 Professor Titular da Faculdade de Economia, Administração e Contabilidade de Ribeirão Preto da Universidade de São Paulo. Endereço para correspondência: Universidade de São Paulo, Faculdade de Economia Administração e Contabilidade, Departamento de Administração. E-mail: dantepm@usp.br.
} 
concebidas, para que os problemas potenciais possam ser visualizados como um todo. Essas políticas têm sido desenvolvidas de forma a contemplar as diferenças das localidades, gerando assim contribuições para a minimização das desigualdades (CAMAROTTI, 2004).

Como a medição é parte inerente no processo de gestão, importante para incentivar programas de desenvolvimento e avaliar seu desempenho, a utilização de indicadores é essencial para tornar viáveis programas que não são claramente compreendidos e para avaliar a extensão de problemas detectados, assim como de suas repercussões (JANNUZZI, 2001).

Nesse contexto, o objetivo deste trabalho é analisar a trajetória do Programa dos Minidistritos Industriais e de Serviços, implantado em São José do Rio Preto (SP), com o intuito de refletir, enquanto modelo de desenvolvimento local, e contribuir com novas formas de avaliação quantitativa, para apontar diferenças locais de desenvolvimento. A ferramenta proposta neste estudo procura construir uma metodologia para análise dos indicadores, relacionados aos objetivos de programas de desenvolvimento local, a partir de dados censitários, possibilitando análise das transformações no desenvolvimento do município de São José do Rio Preto.

\section{Desenvolvimento local e modelos de desenvolvimento}

Vazquez-Barquero (2001) aponta para conjecturas de onde nasceu a teoria do desenvolvimento local. Essa teoria sugere que as externalidades são condições para o desenvolvimento das cidades ou de regiões, e que o aglomerado de empresas contribui para a geração de novas frentes ou mercados, que dinamizam a economia. Mas, diferentemente da teoria do desenvolvimento, o desenvolvimento local não considera o tamanho das empresas, mas o sistema de empresas existentes.

Outros autores sugerem que, no contexto local, não existe somente um caminho a ser percorrido para se incentivar o desenvolvimento. Ele pode ser influenciado pela articulação de diversas atividades ou setores competitivos, derivada da vocação e do interesse da comunidade (GAROFOLI, 1993; 2002; ÁVILA, 2000).

Na Europa e no Canadá, por exemplo, o desenvolvimento foi impulsionado com o apoio às pequenas empresas na área rural, de forma distinta de outras localidades que incentivaram o desenvolvimento industrial baseado em grandes empresas (GALVÃO, 1999; 2004). Outro estudo, comparando as políticas de desenvolvimento local no Canadá e nos Estados Unidos, mostrou cidades que investem em serviços públicos, no melhoramento urbano, na agilidade de processos burocráticos, na promoção de atividades e em eventos para promoção dessas cidades (REESE e ROSENFELD, 2004). 
Baseados em diversas experiências, alguns pesquisadores têm construído diferentes tipologias de modelos de desenvolvimento local (STORPER e HARRISON, 1991; GAROFOLI, 1993; JOYAL, 2002; DUPUIS, 1995). Há uma pluralidade de modelos de desenvolvimento, que revelam as bifurcações de processos de atividades e responsabilidade dos atores sociais locais no controle das transformações do sistema econômico e social (CHIASSON, 2003). Em comum, esses modelos enfatizam a importância de incentivar a criação de pequenos negócios no âmbito local como incentivo ao desenvolvimento.

Os pequenos empresários surgem quando existe o favorecimento para suas atividades na área comercial, na imigração, na área agrícola, na posse da terra e na formação de cultura empreendedora (GALLICCHIO, 2002; ALGABLI e MACIEL, 2002). Obviamente, a utilização da mão de obra local, como suporte a esses empreendimentos, favorece a acumulação de capital local.

Estudos mostram que o ambiente local tem uma função-chave de incentivo para a formação de novas empresas. Autores como Scott e Storper (2003) acreditam que as aglomerações podem ser um fator-chave para impulsionar o desenvolvimento local. Isso se reflete em fatores econômicos, como a importância das interrelações e da troca de informações; outras pesquisas afirmam ainda que locais que possuem grandes concentrações de pequenas empresas têm, provavelmente, maiores taxas de formação de outras empresas (O'FARREL e CROUCHLERY, 1984; LLOYD e DICKEN, 1979).

Ao mesmo tempo, outros estudos apontam que a formação dos indivíduos é um fator que influencia a criação de novas empresas, com médias maiores de criação em áreas com altas proporções de mão de obra qualificada (GOULD e KEEBLE, 1984; WHITTINGTORN, 1984). De acordo com Cross (1981), as pequenas empresas são as melhores incubadoras de capacidade empresarial.

Outro fator interessante é que a urbanização em determinada localidade é ocasionada pela formação de novas empresas. As áreas metropolitanas acabam tendo maiores taxas de criação de novas empresas devido à estratégia de aglomeração (LEONER e STRUYK, 1976).

Estudos apontam efeitos nem sempre suficientes para desencadear um processo de desenvolvimento local, baseado na geração de empresas industriais (FRITSCH e MUELLER, 2004). Uma das alterações se dá na configuração do mercado de trabalho, que não demanda necessariamente mão de obra qualificada. No modelo de produção flexível existe uma perspectiva de responsabilidades quanto ao treinamento dos funcionários para o novo sistema de produção (PIORE e SABEL, 1984), e isso poderia gerar melhores salários. Mas estudos 
evidenciam que países com alto crescimento do número de empregos na área de tecnologia estão relacionados a baixos salários (KLAK, 1989).

A teoria sugere que cada local tem sua própria trajetória de desenvolvimento, mas que nem sempre se comporta de modo inovador, e para isso é preciso desenvolver novas capacidades no sistema produtivo (COELHO, 2000; 2001). No campo de políticas, os estímulos governamentais tradicionais têm sido a parceria com bancos para a concessão de crédito, a criação de entidades para auxílio de gestão, a disponibilização de terrenos ou locais apropriados para o desenvolvimento de indústrias, gastos com infraestrutura local, entre outros (HILHORST, 1975).

O aspecto político, componente do desenvolvimento local, refere-se à capacidade de adequação política às mudanças econômicas, sociais, que ocorrem em uma determinada região, com modificações nas influências no poder, provindas do surgimento de novos grupos sociais. Da mesma forma, são importantes as relações de interesse que se estruturam em torno das organizações de diversos tipos.

No aspecto administrativo, o desenvolvimento auxilia a evolução da gestão pública, em todos os níveis - local, estadual e nacional -, uma vez que a descentralização exige procedimentos mais flexíveis para se adequar às mudanças do ambiente, principalmente no que diz respeito à utilização dos recursos (SUAREZ, 1993).

Ainda é necessário ressaltar que a teoria do território dá suporte às concepções do desenvolvimento local. De acordo com Sachs (1986), cada local possui sua história, trajetória institucional, econômica, social e organizacional que, ao longo do tempo, constrói sua própria identidade e lhe possibilita responder aos desafios vigentes.

Várias pesquisas desenvolvidas sugerem que, quando a decisão dos rumos de desenvolvimento é tomada com a participação da população, as regiões criam suas próprias estratégias, em um processo ativo e dinâmico (BECKER e WITTMANN, 2003; BOISIER, 2001; BOURDIN, 2001; BUARQUE, 2004; MARTINELLI e JOYAL 2004; BANDEIRA, 1999).

A partir desse quadro teórico, a próxima seção do trabalho avança no entendimento de um programa governamental, criado para a promoção do desenvolvimento local.

\section{A trajetória do programa dos minidistritos industriais}

Na década de 1970, São José do Rio Preto apresentou um acentuado crescimento populacional. Esse crescimento originou dois grandes desafios para a administração local: de um lado, como acomodar a crescente população em condições satisfatórias; de outro, como oferecer emprego 
e renda para essa população. A solução foi baseada na criação de micro e pequenas empresas, a partir do Programa dos Minidistritos Industriais.

Os primeiros estudos para a implantação dos minidistritos datam de 1982, com alterações na lei de zoneamento, reorganização do espaço urbano, delimitação para o estabelecimento da área industrial na cidade e criação da zona de expansão urbana. Foram realizados diversos debates e fóruns, no período de 1984 a 1988, para captar sugestões, que foram incorporadas no Plano Quinquenal de Participação Comunitária, entre outras iniciativas que foram importantes para a viabilização do programa e consenso dos interessados.

Já na década de 1970, foi criado o Programa dos Distritos Industriais, com o intuito de incentivar a instalação e ampliação de empresas industriais para a geração de emprego e renda e facilitar para os empresários o acesso a terrenos. Foram criados três distritos, voltados para as empresas de médio e grande porte: Dr. Waldemar de Oliveira Verdi, Dr. Carlos de Arnaldo e Silva e Dr. Ulysses da Silveira Guimarães.

Diferentemente do programa dos distritos, o programa dos minidistritos teve como objetivo apoiar institucionalmente o desenvolvimento das pequenas e médias empresas no município, mas de forma diferenciada das políticas praticadas até então no Estado de São Paulo. Desde seu início, a estratégia não era doar, mas vender os terrenos, sem concessão de subsídios ou isenção de impostos ou taxas (BOLÇONE, 2001).

As principais estratégias desse programa eram intervir no espaço urbano e promover a integração entre a habitação popular e a atividade de micro e pequenas empresas. A política de desenvolvimento urbano de Rio Preto foi redesenhada e, nessa mesma época, articulava-se a política habitacional municipal, que no final da década de 1980 foi consolidada sob forma de lei (n. $\left.{ }^{\circ} 4477 / 88\right)$, com oferta de lotes urbanizados.

A concepção inicial do programa apoiava-se na visão de que o desenvolvimento local devia fundamentar-se no incentivo à industrialização. Diante dos diversos problemas apontados por diagnósticos realizados pela prefeitura, como o documento Perfil Municipal, foram sugeridos diversos projetos para o município cujo conteúdo demonstrava preocupação com as condições em que se encontravam as pequenas empresas, especificamente no setor industrial. Partindo das análises e recomendações do relatório Perfil Municipal, optou-se, então, pelo apoio ao programa de incentivo às pequenas empresas de base industrial.

O Programa dos Minidistritos Industriais contemplou três grandes objetivos em diversas dimensões. No plano econômico, o programa buscava ser uma alternativa para a geração de emprego e renda. Para isso, a prefeitura apostava na criação de novos polos de desenvolvimento

CADERNOS GESTÃo PÚBLICA E CIDADANIA, V. 14, N. 55 - JUL./DEZEMBRO DE 2009 
(os minidistritos), para descentralizar as atividades da região central da cidade. Essa descentralização, por sua vez, conduziria o desenvolvimento às regiões de menor renda, que se localizavam nos bairros periféricos do município, e onde foram instalados os minidistritos. Os incentivos econômicos às micro e pequenas empresas favoreciam a aquisição dos lotes para a instalação de suas dependências, uma vez que a política não era baseada na doação de terrenos, mas facilitava as condições de pagamento.

Em termos sociais, o objetivo era incrementar a renda da população menos favorecida, buscando aproximar o local de trabalho e suas moradias, diminuindo assim o gasto com transporte. O trabalho feminino também era um dos focos do programa, uma vez que os dados revelavam que era cada vez maior o número de mulheres chefes de famílias na cidade. Sendo assim, era necessário criar condições para que houvesse uma inserção da mulher no mercado de trabalho.

Buscava-se, também, dissipar o desenvolvimento para regiões que eram consideradas menos desenvolvidas, com o objetivo primordial de melhorar as condições de vida da população que circundava as regiões onde seriam instalados os minidistritos. Esperava-se, dessa forma, um melhor ordenamento, tanto no espaço físico construído para a implantação das micro e pequenas empresas, bem como no atendimento às necessidades dos bairros onde estariam localizadas as empresas.

Outra condição primordial está relacionada com a qualidade de vida dos bairros vizinhos, de modo a separar a atividade industrial da convivência das famílias e localizá-los próximos aos equipamentos urbanos de saúde, educação, assistência à família e aos centros comunitários (BOLÇONE, 2001).

\section{O programa dos minidistritos industriais como modelo de desenvolvimento}

Com o foco estruturado nos distritos industriais, o programa aplicado foi construído com base na estratégia de enfrentar as condições de estagnação e diferenças de desenvolvimento, visualizadas na cidade no início da década de 1970. O modelo apresentado teve como objetivo principal o auxílio a criação, suporte, elevação e melhoria de produtividade das pequenas e médias empresas do setor industrial, assim como atender necessidades básicas da população. Dessa forma, o modelo considerava como fator prioritário o fortalecimento da indústria e, com sua evolução, o incremento de outros setores, como o de serviços, fazendo com que houvesse uma diversificação da economia ao longo dos anos. Criou-se, assim, um sistema de

CADERNOS GESTÃo PÚBLICA E CIDADANIA, V. 14, N. 55 - JUL./DEZEMBRO DE 2009 
serviços e oportunidades de trabalho, garantindo a fixação da população e intensificando o poder de atração da cidade.

O conteúdo da estratégia do programa é mostrado na Figura 1:

Figura 1 - Modelo de desenvolvimento integrado local industrial.

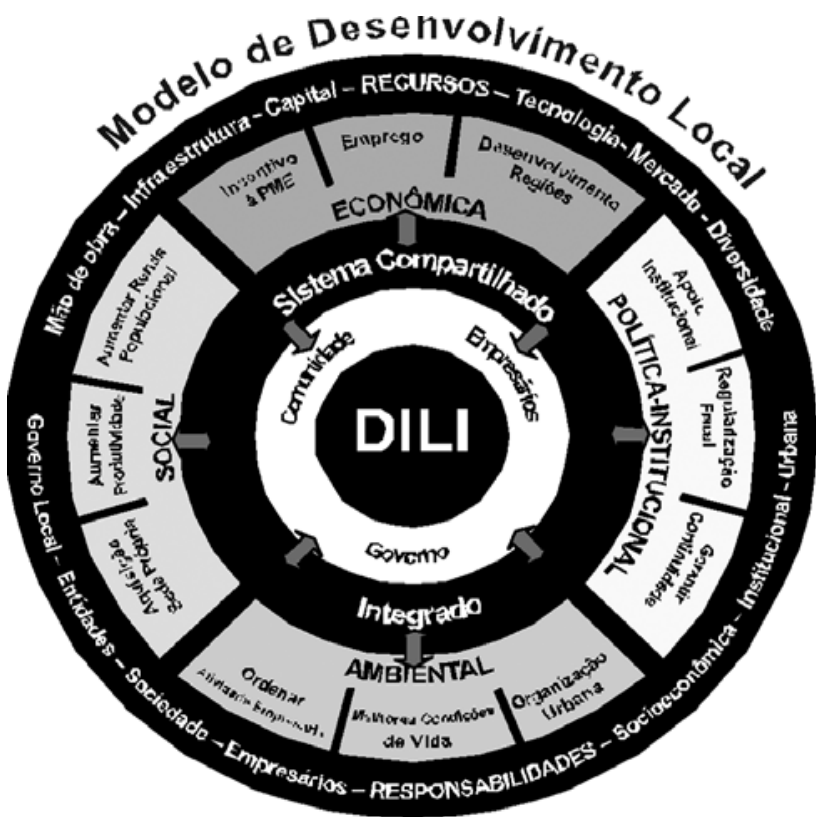

Fonte: Elaborado pelos autores

Partindo-se da análise do programa, concluiu-se que:

a) O desenvolvimento pode ser o resultado da coordenação, em nível municipal, dos objetivos plantados por meio de políticas de desenvolvimento em nível local;

b) O crescimento do número de empresas industriais consiste na chave para o incentivo do desenvolvimento, e seu fomento engloba o incentivo ao desenvolvimento simultâneo de outros setores da economia;

c) O desenvolvimento envolve aspectos sociais, econômicos, ambientais e políticoinstitucionais. Portanto, o planejamento deve conter fatores que envolvam as dimensões conjuntamente;

d) As forças sociais devem desempenhar um papel importante no desenvolvimento local, posto que ele é resultado dos esforços de um grande número de empresários individuais, 
cuja disposição e habilidade para participar em qualquer programa ou ação de mudança são essenciais.

O modelo de desenvolvimento local compreende, em parte, um tratamento coordenado dos três setores econômicos e, de outra parte, os diversos níveis espaciais (empresários, sociedade, entidades e governo local), buscando resolver os problemas socioeconômicos, institucionais e físicos do desenvolvimento.

\section{Procedimentos metodológicos para a análise e a avaliação quantitativa do programa}

Nesta sessão, apresenta-se a parte quantitativa do estudo, enfatizando a importância de medidas, no âmbito local, de auxílio às potencialidades locais. Outro ponto importante é quanto à medição das possíveis influências geradas por uma política pública no âmbito local.

Para verificar até que ponto o programa dos minidistritos incentivou o desenvolvimento dos bairros atendidos pelo programa, os setores censitários foram delimitados como unidade de análise. Esses setores censitários são utilizados pelo IBGE como fonte de coleta de dados, obedecendo a critérios de operacionalização de modo a abranger uma área que possa ser percorrida por um único recenseador em um mês, e que possua em torno de 250 a 350 domicílios, em áreas urbanas (FIOCRUZ, 2006).

As variáveis disponíveis para a análise, por setores censitários, representam as dimensões consideradas nos objetivos do programa, assim como possibilitam a visualização por meio de mapas. Para a identificação das possíveis contribuições, foi aplicado Teste de Aglomerado, para melhor comparação dos setores e classificação dos setores em clusters. O teste foi aplicado com base nos dados dos setores censitários fornecidos pelo Censo Demográfico do Instituto Brasileiro de Geografia e Estatística (IBGE) de 2000, utilizando 12 variáveis escolhidas.

As variáveis foram escolhidas baseadas na literatura e nos objetivos do programa dos minidistritos. Na dimensão econômica, foram estipulados três níveis de renda de acordo com os dados disponibilizados pelo Censo e correspondentes à faixa salarial dos chefes de família: renda baixa (abaixo de dois salários mínimos), renda média (entre 2 e 10 salários) e renda alta (acima de 10 salários).

Na dimensão social, foi selecionada a variável rendimento das mulheres chefes de família, comparando com renda total dos chefes de famílias. O programa menciona que o minidistrito

CADERNOS GESTÃo PÚBLICA E CIDADANIA, V. 14, N. 55 - JUL./DEZEMBRO DE 2009 
pode ser um fator gerador de empregos para as mulheres, auxiliando na igualdade de oportunidades. A escolha da variável população, de 22 a 44 anos, evidencia a presença de espírito jovem e empreendedor no setor censitário. Também foram incluídas variáveis de escolarização.

Na dimensão ambiental, foram selecionadas duas variáveis: densidade habitacional (número de pessoas por domicílio), que expressa melhor qualidade de vida, e o número de domicílios quitados.

Na dimensão político-institucional, as variáveis que demonstram os serviços oferecidos pelo poder público são: abastecimento de água na rede geral, destino do lixo - coletado e esgotamento sanitário - na rede geral.

As variáveis foram transformadas para uma escala de 0 a 1 , fazendo as divisões necessárias e eliminado os outliers. Dos 432 setores censitários do município, foram utilizados para a análise 427. Os setores eliminados apresentavam dados nulos comprometendo a análise, principalmente com relação a renda e idade.

Para análise dos dados foi utilizado o programa Statistical Package Social Science (SPSS), versão 8.0, visando a melhor tratamento e resultados fidedignos.

Como procedimento para analisar o impacto da multicolinearidade, foi rodado um teste para agrupar as variáveis. O resultado mostrou a formação de três clusters com distribuição semelhante das variáveis entre cada um. Como método de aglomeração optou-se por utilizar o método hierárquico, para estabelecer o número de agrupamentos, e para a caracterização dos centros dos clusters.

Para escolha do número de agrupamentos foram utilizados os seguintes critérios: (a) a razão da variância total dentro do grupo para a variância entre grupos e (b) análise do dendograma. Como saída, foram classificados 4 grupos com características diferentes. Para chegar a esse valor, foi testado o método hierárquico e compararam-se os resultados com o método não hierárquico. Foi também utilizada análise de gráficos boxplot e a análise descritiva dos dados. Com esses procedimentos, houve uma preocupação em determinar uma quantidade de clusters que fossem condizentes com as diferenças entre os grupos gerados.

Os clusters foram criados com o intuito de compreender a diversidade do município e, com a posterior identificação da localidade dos minidistritos industriais, auxiliar na determinação das características predominantes da região em que eles estão inseridos.

CADERNOS GESTÃo PÚBLICA E CIDADANIA, V. 14, N. 55 - JUL./DEZEMBRO DE 2009 


\section{Análise dos dados}

$\mathrm{Na}$ análise quantitativa, utilizando análise de agrupamentos, foram gerados quatro clusters. Cada um foi agrupado com um número determinado de setores censitários. O primeiro possui 177 dos setores censitários (41\% dos casos); o segundo, 26 setores (6\%); o terceiro, 166 setores (39\%); o quarto, 58 setores (13,6\%). Mesmo sendo diferente o número de casos em cada um dos agrupamentos realizados, é valido afirmar que essa variabilidade não interfere na identidade do cluster.

Caracterizando cada um dos clusters gerados, foram analisadas as disparidades de faixas de renda mostradas na Figura 2. O primeiro cluster apresentou $60 \%$ dos chefes de famílias com renda média (de 2 a 10 salários), 23\% com baixa renda e menos de $20 \%$ com renda maior que 10 salários. O cluster com maior proporção de pessoas com renda alta foi o cluster 2.

No cluster 3, onde estão localizados 11 dos 13 minidistritos, a renda predominante é a renda média. Nesse cluster também consta a maior proporção de pessoas de baixa renda (mais de $30 \%$ ). No cluster 4 , mais de $40 \%$ possui renda alta e $50 \%$ dos chefes de família possuem renda média. Nota-se que um dos objetivos do programa era auxiliar as regiões periféricas no incremento da renda da população. Comparando os dados dos clusters, pode-se dizer que a disparidade de rendimentos ainda é acentuada.

Figura 2 - Dados médios das faixas de renda em cada cluster gerado

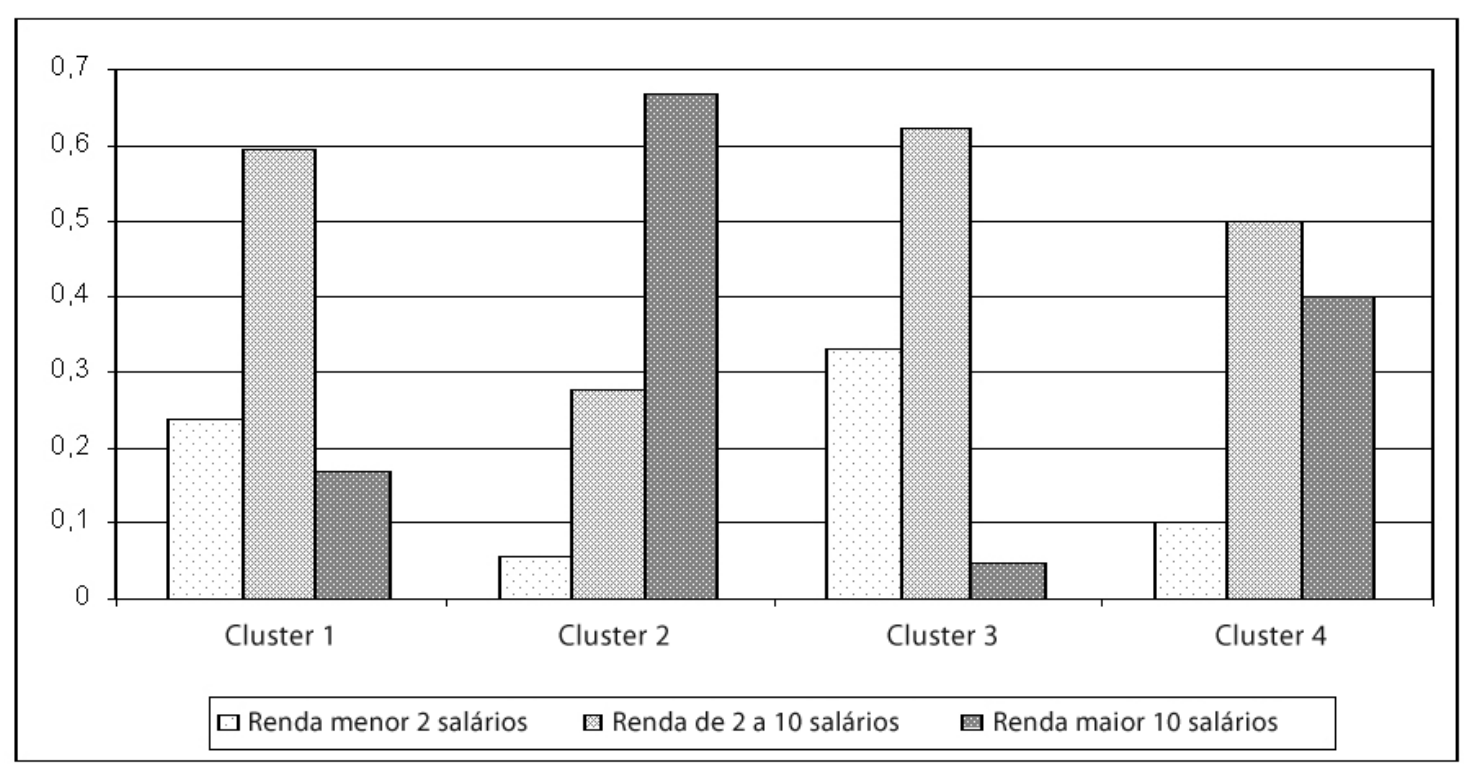

Fonte: Elaborado pelos autores. 
Na dimensão social, mostrada na Figura 3, no que se refere à porcentagem do rendimento das mulheres em comparação com o rendimento total dos chefes de família, verifica-se que as mulheres ainda ganham menos que os homens. Nos cluster 3 e 1 , que possuem minidistritos, o rendimento das mulheres equivale a somente $15 \%$ do total dos rendimentos. O maior valor visualizado é no cluster 4, mas não passa de $25 \%$ do total. A porcentagem da população entre 22 e 44 anos é quase semelhante em todos os aglomerados, não apresentando diferenças significativas.

Figura 3 - Dados médios da proporção do rendimento das mulheres e população de 22 a 44 anos em cada cluster gerado

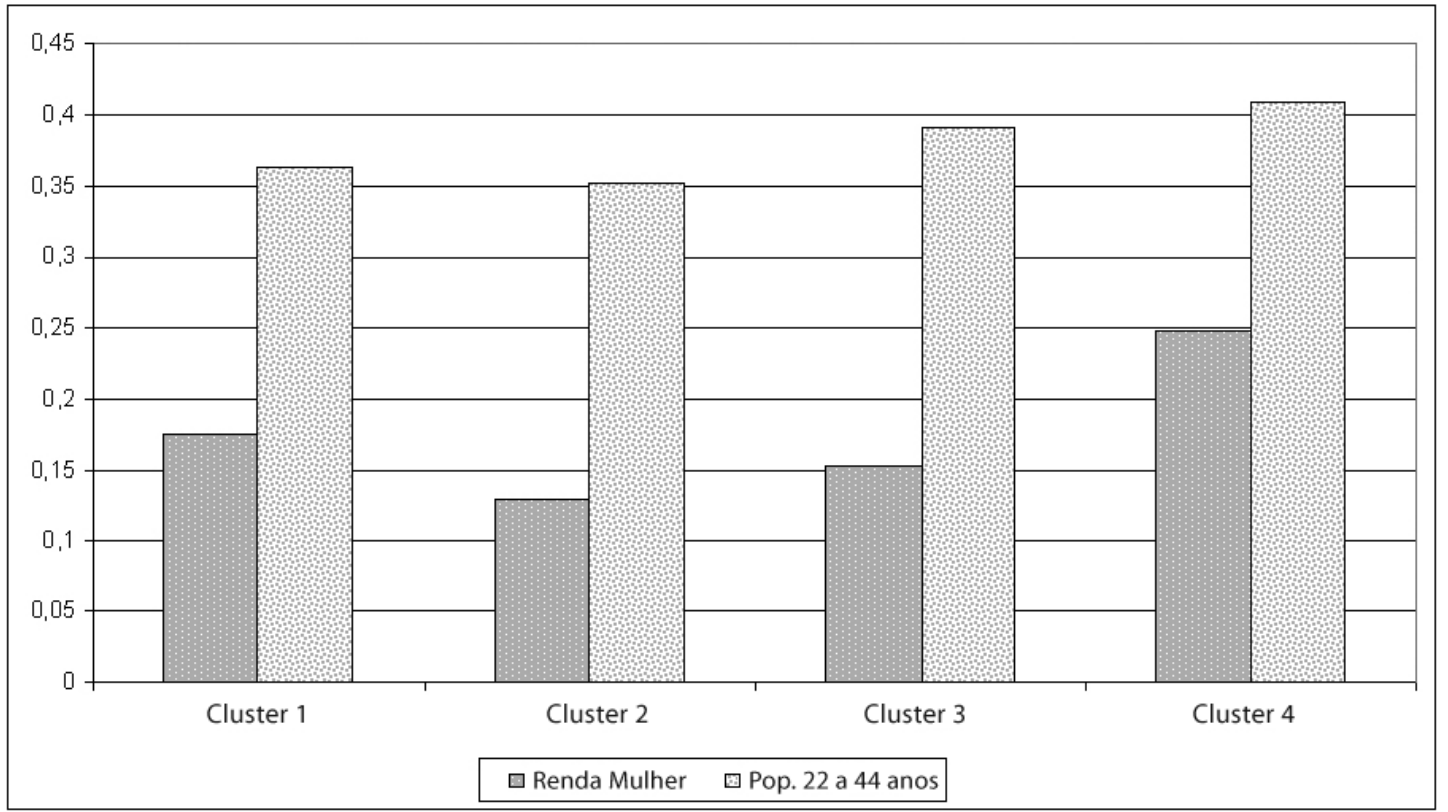

Fonte: Elaborado pelos autores.

Quanto ao nível educacional da população em cada cluster, mostrado na Figura 3, pode ser analisado que no cluster 3 a disparidade entre aqueles que possuem nível superior e não possuem é maior do que todos os outros. Enquanto somente 3\% dos chefes de família atingem o nível superior, $89 \%$ possuem ensino fundamental ou escolaridade inferior. No cluster 1 , $12 \%$ dos chefes possuem graduação. O cluster 2 é o que apresenta os melhores dados de escolaridade. 
Figura 4 - Dados médios do nível educacional em cada cluster gerado

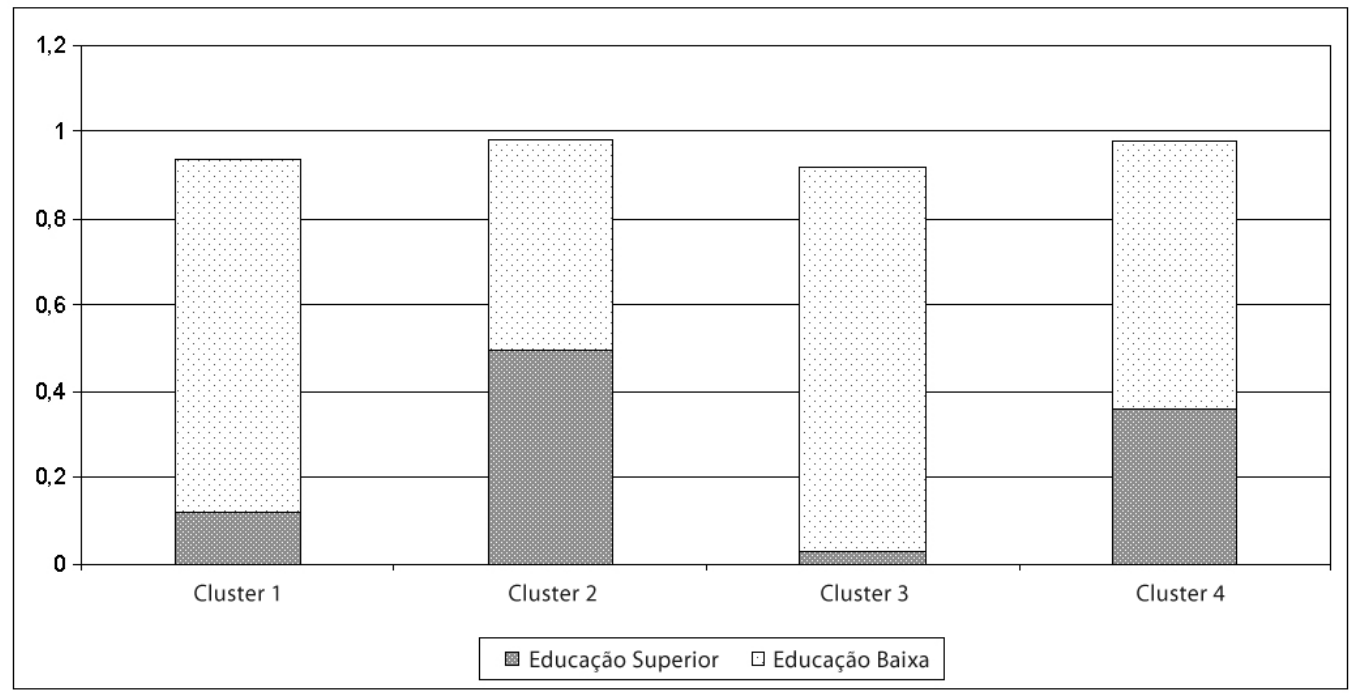

Fonte: Elaborado pelos autores.

Na dimensão ambiental, mostrada na Figura 5, foram analisadas duas variáveis: densidade habitacional (número de moradores por domicílio) e domicílios próprios já quitados. O número de domicílios quitados é maior no cluster 2 (71\%), acompanhado do cluster 3 (56\%), do cluster 1 (56\%) e, por último, do cluster 4 (47\%). A conciliação do programa dos minidistritos com o programa habitacional talvez tenha auxiliado a aquisição de moradia no cluster 3.

Figura 5 - Dados médios da densidade habitacional e domicílios quitados em cada cluster gerado

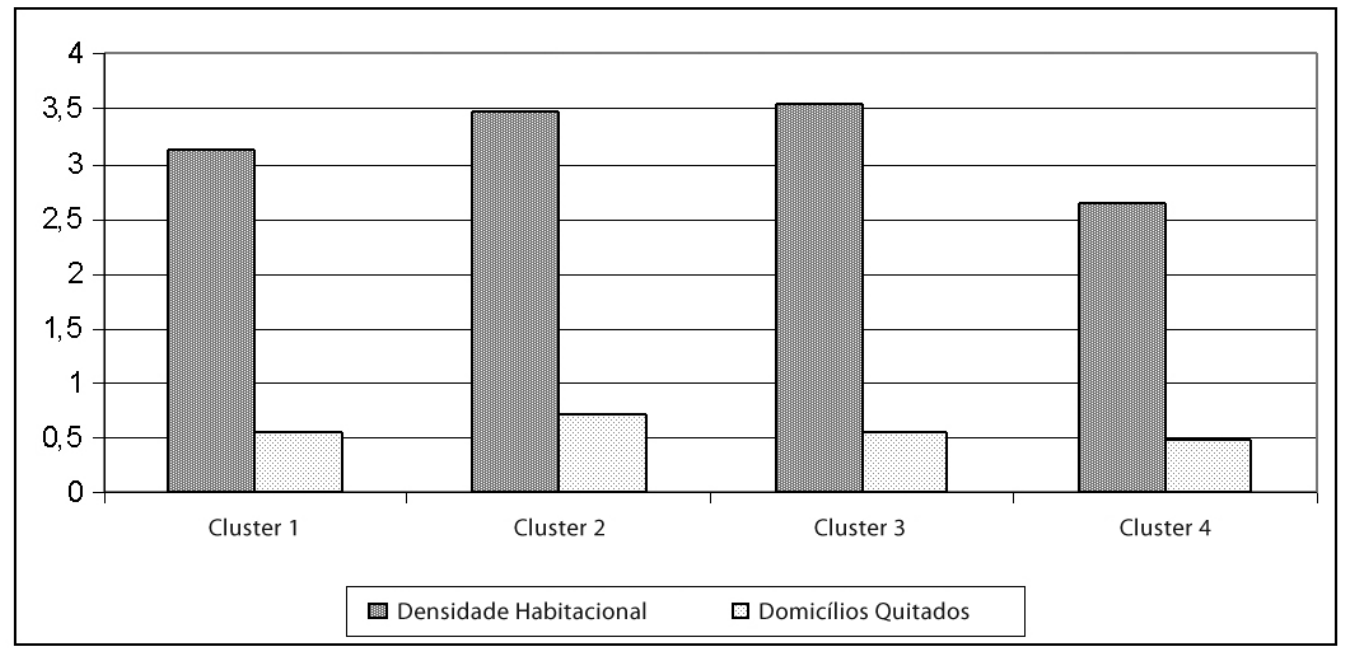

Fonte: Elaborado pelos autores. 
A densidade habitacional é menor na região central de Rio Preto e é maior nas regiões norte e sul, representadas pelos clusters 2 e 3, em uma das áreas que possui minidistritos. A existência de empresas industriais pode ter influenciado a maior ocupação nessa região, sendo que o cluster 2 possui distrito industrial, projetado para grandes empresas.

Figura 6 - Mapa de localização dos setores e clusters gerados

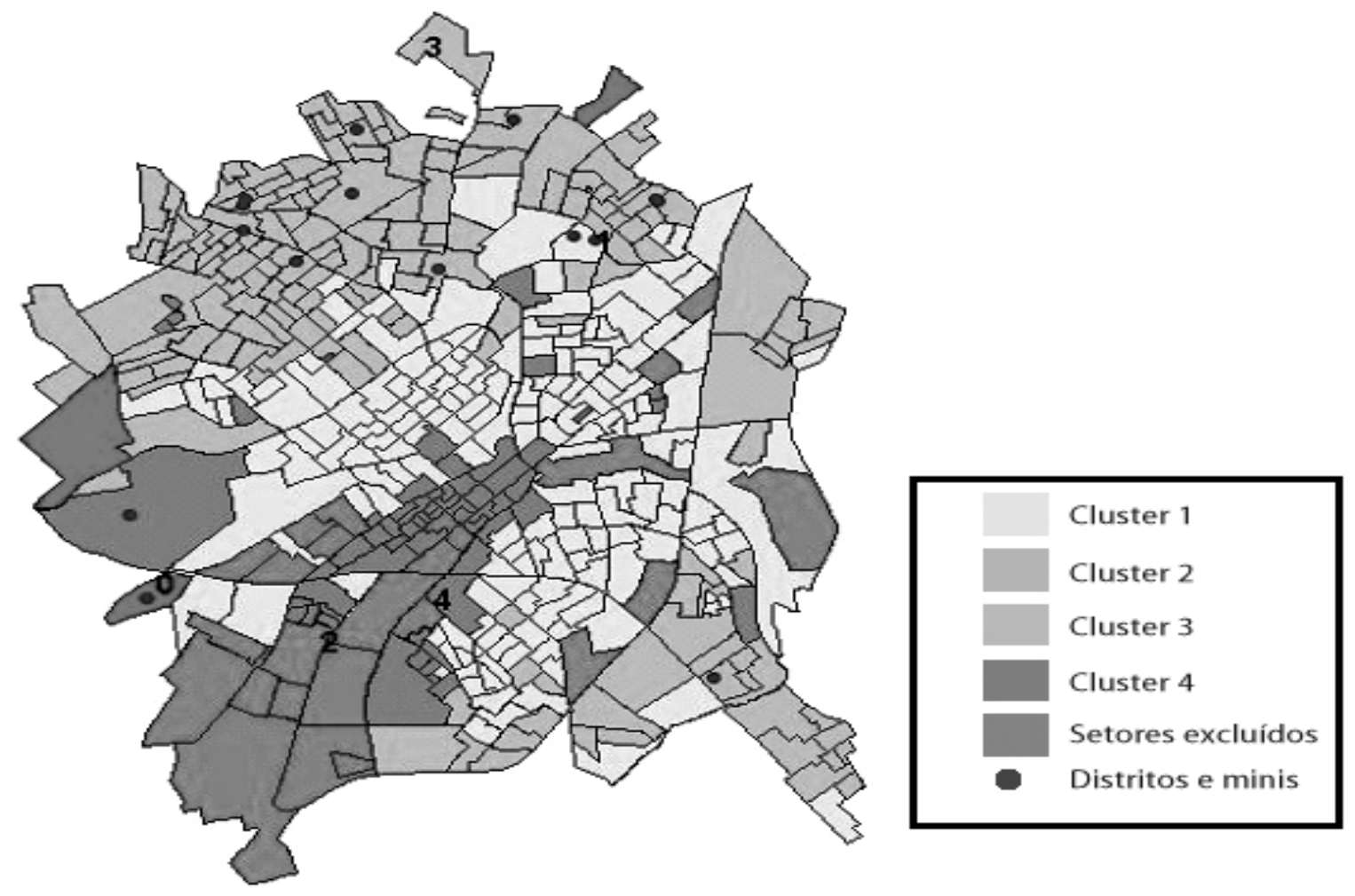

Fonte: Elaborado pelos autores.

No quesito político-institucional, três variáveis entraram na análise: abastecimento de água, rede geral de esgoto e coleta de lixo. Essas variáveis não apresentaram diferenças entre os clusters, mostrando-se com altos valores para todos, de quase $100 \%$. No cluster 4 o abastecimento de água chega somente a $80 \%$ dos domicílios.

Foram estipulados critérios para classificação dos clusters e construiu-se um quadro com a nomeação dos valores estabelecidos. O cluster com melhor classificação foi o cluster 4 . Em seguida o cluster 2 , o cluster 1 e por último o cluster 3. 
O cluster 4 apresentou a melhor classificação na dimensão social e a segunda melhor na dimensão econômica. O cluster 2 é o melhor colocado na dimensão econômica e o segundo na social. Já o cluster 1 mostra a terceira melhor classificação econômica e a primeira na dimensão político-institucional, juntamente com o cluster 3, que em outras dimensões foi o pior classificado, com rendas menores e com nível de escolaridade mais baixa. Nota-se que educação e renda são dois fatores interligados.

Com o auxílio de software de geoprocessamento ArcExplorer ${ }^{\mathrm{TM}}$ 9.2.0 - Java edition, foram identificados os setores censitários e procedeu-se à classificação com a aplicação do teste de agrupamento. Isso é mostrado na Figura 6.

Cada setor foi classificado nos clusters designados e, pela visualização do mapa, foi possível identificar a localização dos setores nos minidistritos. Com isso criou-se uma ferramenta por meio de agrupamento que possibilita melhor constatação da política pública implantada e suas repercussões.

A localização dos minidistritos pode ser identificada pelos pontos azuis no mapa. O mapa construído mostra que as regiões que possuem minidistritos são identificadas pelo cluster 3 , com menor pontuação. Os setores excluídos também foram mostrados, mas sem classificação.

Nos clusters com minidistritos, nota-se que a proporção de pessoas com baixa renda é maior que nos outros clusters gerados. Enquanto os clusters que não possuem minidistritos apresentam menos de $10 \%$ dos chefes com menos de 2 salários, para os que possuem minidistritos passa de $20 \%$ para o cluster 1 e de $30 \%$ para o cluster 3 . Isso comprova que os minidistritos estão localizados em regiões cujas iniciativas públicas de incremento de renda são necessárias.

Na dimensão social, os clusters com minidistritos também apresentam o número de pessoas com menor escolaridade, enquanto nos clusters 2 e 4, sem minidistritos, a escolaridade é maior, mas não ultrapassa 50\% dos chefes de família. É digno de nota o baixo número de pessoas com o ensino superior no cluster 3, onde está localizada a maioria dos minidistritos: somente $3 \%$.

É notável a relação entre a renda e escolaridade: quanto maior a renda, maior o nível de escolaridade. Quando na literatura menciona-se que a existência de empresas industriais está associada à maior escolaridade da população, isso não se aplica a São José do Rio Preto. Talvez pela própria designação do programa, os minidistritos foram localizados nessas áreas justamente para auxiliar o seu desenvolvimento.

Quando se analisam os dados de rendimento das mulheres, verifica-se que a equidade ainda é um ponto a ser trabalhado, não só nas regiões que possuem distritos, mas em todo o município.

CADERNOS GESTÃo PÚBLICA E CIDADANIA, V. 14, N. 55 - JUL./DEZEMBRO DE 2009 
Seu rendimento ainda não ultrapassa os $20 \%$ do rendimento total (o salário dos homens chefes de família representa aproximadamente 80\%). Diferentemente das outras análises, os clusters que possuem minidistritos (clusters 1 e 3) apresentam melhores resultados. Isso pode ser resultado do incentivo à formação de empregos e do incremento da renda das mulheres, por meio dos minidistritos.

A presença de jovens no município pode ser notada em todos os clusters. A quantidade da população, entre 22 e 44 anos, é semelhante em todos os aglomerados, sendo que os clusters 3 e 1 apresentam a segunda e a terceira maior quantidade. A população jovem pode ser um fator que incentiva o surgimento de empresas nos minidistritos.

Os maiores resultados de domicílios quitados estão nos clusters que possuem minidistritos. Isso pode ter sido influência da conciliação do programa dos minidistritos com o programa habitacional. Na densidade habitacional, percebe-se que nas localidades com minidistrito o aglomerado de pessoas é maior.

A dimensão político-institucional não apresentou muita influência na determinação dos clusters, apresentando poucas diferenças entre eles.

De forma geral, há evidências de que os setores que possuem minidistritos apresentam condições econômicas e sociais que evidenciam diferenças, quando comparados com outras regiões. A proporção do crescimento populacional, assim como do número de pessoas jovens na economia, mostra a importância de estrutura social que reforça o espírito empreendedor.

\section{Conclusões}

O local deve ser capaz de superar as dificuldades frente às mudanças impostas pela globalização e atender às necessidades da população (BOURDIN, 2001). Para isso, é preciso fixar a população em seu território e incentivar as pequenas empresas, nas diversas atividades e setores, assim como criar alternativas para o desenvolvimento industrial que não seja focado nas grandes corporações (VAZQUEZ-BARQUERO, 2001). Isso faz com que as cidades e regiões possam ser mais competitivas e fortaleçam suas comunidades locais, buscando impulsionar o desenvolvimento local.

O Programa dos Minidistritos Industriais reflete uma dimensão teórica calcada no desenvolvimento local e no apoio às pequenas empresas, com foco no desenvolvimento das regiões periféricas da cidade de São José do Rio Preto. Com a política, incentivou-se a abertura de empresas na área industrial, sendo um incentivo diferencial que privilegiou os potenciais

CADERNOS GESTÃo PÚBLICA E CIDADANIA, V. 14, N. 55 - JUL./DEZEMBRO DE 2009 
locais e o maior envolvimento do programa em problemas que afligiam a cidade - como habitação, ordenamento territorial, entre outros.

O desenho do modelo mostrou que políticas que focam na geração de emprego e renda, elementos que contribuem para o desenvolvimento econômico da região, devem ser fundamentadas no desenvolvimento endógeno. Ou seja, para um melhor direcionamento dessas políticas, são necessários a identificação e o aproveitamento das potencialidades de cada local.

A análise do programa ilustra a relação entre aspectos econômicos, sociais, ambientais e políticos, fatores importantes nas políticas de desenvolvimento. Para o fortalecimento do potencial de desenvolvimento, o programa mostra-se com uma estratégia de ação que intensifica as capacidades locais, como recomendado por autores a respeito de iniciativas locais (COFFEY e POLISE, 1984; 1985; GALVÃO, 2004; VAZQUEZ-BARQUERO, 2001).

Além da análise do programa e contribuição para o desenho de novas políticas, por meio da experiência de São José do Rio Preto, foram utilizados indicadores, com análise por setores censitários, para verificar o impacto do programa nas diferentes regiões da cidade. Uma análise quantitativa foi apresentada para fins de constatar quais fatores poderiam ter sido influenciados pelo programa dos minidistritos em cada cluster, gerado na análise, onde estão localizadas as empresas.

Percebeu-se que as regiões que possuem minidistritos são as mais carentes, principalmente nas áreas de renda e educação. Isso evidencia a necessidade de implantação de outras políticas públicas conciliadas ao programa. Quando se analisam os dados de rendimento das mulheres, verifica-se que a equidade ainda é um ponto a ser trabalhado, não só nas regiões que possuem distritos, mas em todo o município de São José do Rio Preto. A existência de espírito empreendedor é presente em todos os setores censitários estudados, e isso pode auxiliar a criação de novas empresas.

Os minidistritos estão localizados em regiões com maior aglomeração populacional, tendo a crer que a existência do programa pode ter sido um dos motivos que incentivaram o crescimento populacional na cidade.

Quanto às implicações para políticas públicas em desenvolvimento local, o apoio às pequenas e médias empresas aproveita as potencialidades locais e favorece a formação de outras novas empresas, até mesmo em outros setores. Além disso, pode repercutir no favorecimento de novos projetos estruturantes e de maior amplitude para a cidade. Conforme o crescimento da cidade, o programa ganha novas proporções, sendo necessário criar outros incentivos para que a política tenha continuidade e persevere.

CADERNOS GESTÃo PÚBLICA E CIDADANIA, V. 14, N. 55 - JUL./DEZEMBRO DE 2009 
O aproveitamento das potencialidades de desenvolvimento e dos recursos existentes é fundamental para a continuidade da proposta, principalmente no tocante às pequenas empresas, para que fatores e organizações externas não tenham domínio total sobre os potenciais econômicos locais. Consequentemente, a introdução de empresas industriais necessita de serviços de outras empresas, como prestadoras de serviços, pessoas com qualificação, novos centros de formação, auxílio aos empreendedores, para evitar altas taxas de mortalidade, principalmente nos primeiros anos de instalação.

Os efeitos proporcionados por um programa são maiores quando existe um sistema que engloba outras áreas ou quanto há uma integração de objetivos. Se não há articulação dos resultados e dos objetivos do projeto, as ações governamentais funcionarão de forma desagregada.

A contribuição deste estudo deve-se à utilização de instrumentos qualitativos e quantitativos para análise de políticas públicas. Isso possibilitou a construção do modelo do Programa dos Minidistritos Industriais e a utilização de indicadores por setores censitários para uma análise microrregionalizada.

\section{Referências}

ALBAGLI, S.; MACIEL, M. L. Capital social e empreendedorismo local. Proposição de políticas para a promoção de Sistemas Produtivos Locais de Micro e Pequenas Empresas. Redes de Sistemas Produtivos Inovativos Locais. UFRJ, 2002.

ÁVILA, V. F. Formação educacional em desenvolvimento local: relato de estudo em grupo e análise de conceitos. Campo Grande: UCDB, 2000.

BANDEIRA, P. Participação, articulação de atores sociais e desenvolvimento regional. Texto para Discussão n. 630. Brasília: IPEA, 1999.

BECKER, D.; WITTMANN, M. (Org.) Desenvolvimento regional: abordagens interdisciplinares. Santa Cruz do Sul: EUNISC, 2003.

BOISIER, S. Desarrollo local: ¿De qué estamos Hablando? In: MADOERY, O.; VÁZQUEZ, B. A. (Eds.) Transformaciones globales, instituciones y políticas de desarrollo local. Rosario: Homo Sapiens, 2001.

BOLÇONE, O. J. Minidistritos Industriais: uma política pública de incentivos às micro e pequenas empresas (São José do Rio Preto, 1983-1998). Dissertação de Mestrado da Faculdade de Ciências e Letras da Universidade Estadual Paulista, 2001.

CADERNOS GESTÃo PÚBLICA E CIDADANIA, V. 14, N. 55 - JUL./DEZEMBRO DE 2009 
BOURDIN, A. A questão local. Trad. Orlando dos Santos Reis. Rio de Janeiro: DP\&A, 2001.

BUARQUE, S. C. Construindo o desenvolvimento local sustentável: metodologia de planejamento. Rio de Janeiro: Garamond, 2004.

CAMAROTTI, L. Construção de indicadores de desenvolvimento local. In: CONGRESO INTERNACIONAL DEL CLAD SOBRE LA REFORMA DEL ESTADO Y DE LA ADMINISTRACIÓN PÚBLICA, 9, 2004, Madri. Madri, 2004

CHIASSON, G. Territories and actors in local development: new locus of democracy. Canadian Journal of Political Science - Revue Canadienne de Science Politique, v. 36, n. 1, p. 214-5, 2003.

COELHO, F. D. Desenvolvimento econômico local no Brasil: as experiências recentes num contexto de descentralização. Proyecto CEPAL/GTZ. Desarrollo económico local y descentralización en América Latina. Santiago, Chile: 2000.

COELHO, F. D. Desenvolvimento local e construção social: o território como sujeito. In: SILVEIRA, C. M.; REIS, L. C. (Org.) Desenvolvimento local: dinâmica e estratégias. Rede DLIS, 2001.

CROSS. M. New firm formation and regional development. Aldershot, Hants: Gower, 1981.

DUPUIS, J. P. Le modèle québécois de développement économique: débats sur son contenu, son efficacité sés liens avec les modes de gestion des entreprises. 2. ed. Québec, Canadá: Presses Inter Universitaires, 1995.

FIOCRUZ. Sistema de informação geográfica: setores censitários. 2006. Disponível em: http://www.sig.cict.fiocruz.br/setorescensitarios.htm Acesso em: 20 abr. 2007.

FRITSCH, M.; MUELLER, P. The effects of new business formation on regional development over time. Discussion Papers on Entrepreneurship, Growth and Public Policy, jun. 2004.

GALLICCHIO, E. La experiencia del Centro Latinoamericano de Economía Humana (CLAEH) en la construcción de alianzas para el desarrollo local. Analisis de tres experiencias. Conferencia en Asamblea General de ALOP. Antigua, Guatemala, 9 de mayo de 2002.

GALVÃO, A. C. F.; VASCONCELOS, R. Política regional à escala sub-regional: uma tipologia territorial como base para um fundo de apoio ao desenvolvimento regional. Texto para discussão n. 665. Brasília, 1999.

CADERNOS GESTÃo PÚBLICA E CIDADANIA, V. 14, N. 55 - JUL./DEZEMBRO DE 2009 
GALVÃO, A. C. F. Políticas de desenvolvimento regional e inovação: a experiência da União Europeia. Rio de Janeiro: Garamond, 2004.

GAROFOLI, G. Economic development, organization of production and territory. Revue d'Economie Industrielle, n. 64, p. 22-37, 1993.

GAROFOLI, G. Local development in Europe: theoretical models and international comparisons. European Urban and Regional Studies, n. 9, v. 3, p. 225-239, 2002.

GOULD. A.; KEEBLE, D. New firms and rural industrialization in East Anglia. Regional Studies, n. 18, p. 189-201, 1984.

HILHORST, J. G. M. Planejamento regional: enfoque sobre sistemas. Rio de Janeiro: Zahar, 1975.

JANNUZZI, P. Indicadores sociais no Brasil: conceitos, fontes de dados e aplicações. São Paulo: Alínea, 2001.

JOYAL, A. Le developpement local: comment stimuler l'économie des régions en difficulté. Diagnotic, Les Presses de l’Unversité Laval, 2002.

KLAK T. Does high technology polarize the work force? Environment and Planning C. Government and Policy, v. 7, n. 2, p. 223-241, 1989.

LEONE R. A.; STRUYK. R. The incubator hypothesis: evidence from five SMSAs. Urban Studies, n. 13, p. 325-32, 1976.

LLOYD P. E.; DICKEN P. New firms, small firms and job generation: the experience of Manchester and Merseyside, 1966-75. Working Paper 9. North West Industry Research Unit, University of Manchester, 1979.

MARTINELLI, D. P; JOYAL, A. Desenvolvimento local e o papel das pequenas e médias empresas. São Paulo: Manole, 2004.

O'FARREL, P. L; N.; CROUCHLERY, R. An industrial and spatial analysis of new firm formation in Ireland. Regional Studies, n. 18, p. 221-36, 1984.

PIORE, M. F.; SABEL, C. F. The second industrial divide: possibilities for prosperity. New York: Basic Books, 1984.

REESE, L. A.; ROSENFELD, R. A. Local Economic Development in the United States and Canada: Institutionalizing Policy Approaches. American Review of Public Administration, v. 34, n. 3, p. 277-292, 2004. 
ROLNIK, R.; NAKANO, K. Velhas questões, novos desafios. Cadernos Le Monde Diplomatique, jan. 2001.

SCOTT, A. J.; STORPER, M. Regions, globalization, development. Regional Studies, v. 37, p. 579-593, 2003.

STORPER, M.; HARRISON, B. Flexibility, hierarchy and regional development: the changing structure of industrial production systems and their forms of governance in the 1990s. Research Policy, n. 20, p. 407-22, 1991.

SUAREZ, A. R. El desarrollo regional. Santafé de Bogotá, Colombia: ESAP, 1993.

VAZQUEZ-BARQUERO, A. Desenvolvimento endógeno em tempos de globalização. Porto Alegre: Fundação de Economia e Estatística, 2001.

WHITTINGTORN. C. Regional bias in new firm formation in the UK. Regional Studies, n. 18, p. 253-6, 1984.

Artigo recebido em 09/11/2009. Aprovado em 19/11/2009. 